\title{
Cytogenetical Studies on $F_{1}$ Hybrid of Solonum lucani $X S$. surattense var. violet and white
}

\author{
G. Kumar and S. K. Roy \\ Department of Botany, Banaras Hindu University, Varanasi-221005, India
}

Accepted August 8,1988

Spinous solanums, which are widely distributed throughout the tropical and sub-tropical belts of the world, have great economic importance as vegetable or medicinal plants due to their richness in alkaloid contents (Watt and Brink 1962, Dhar et al. 1974, Heble and Bhatt 1976). The earlier cytogenetical work on them by different authors have indicated that there exists a kind of chromosomal compatibility among most members of spinous Solanum. Yet sterility emerges despite normal pairing of chromosomes at metaphase I, and without any reduction in chiasma frequency in the reductionally dividing PMCs of the hybrids in respect of their parents (Kirti and Rao 1983, Singh and Roy 1986). This type of meiotic behaviour in hybrid plant is unique and different in nature. It shows major deviation from the normal pattern of behaviour of genomes. In this context some hybridization works have been tried between different members of Solanum from India and abroad (Marks 1965, Rao 1981, Kirti and Rao 1981, 1982, Omidiji 1983, Singh and Roy 1986).

In the present investigation genomic relationship was sought for between two members of Solanum having different morphology and ecogeographical distribution. Such works can correctly establish or negate the anticipated relationships between the parent forms.

\section{Materials and methods}

Seeds of $S$. surattense Burm. f. var. violet and var. white were collected from local populations and those of $S$. lucani F. Muell. obtained from Australia through the courtesy of Dr. David E. Symone of the Waite Agriculture Research Institute, Adelaid, Australia. Pure line plants were raised by single selection method. For successful hybridization work old buds ready to open next morning were emasculated in the evening and bagged to avoid unwanted pollination. Hand pollination was done on the following morning with desirable pollen under aseptic conditions. For facilitating pollen germination, stigmas were smeared with nutrient medium as suggested by Brewbeakers and Kwack (1963). Pollinated flowers were rebagged till fruit setting. Crossability index was recorded after Marks (1965).

For meiotic studies, $F_{1}$ buds were fixed in 3:1 ethanol-acetic acid solution for overnight and anthers squashed in $1.5 \%$ propionocarmine. Pollen fertility was scored from the percentage of the pollen that stained well with $1 \%$ acetocarmine. Seed setting/fruit was determined on the average seeds of ten randomly selected fruits of each plant.

\section{Results}

Data on crossability relationships are given in Table 1, which indicates that out of 102 crosses between $S$. surattense var. violet $\times$ lucani, 28 were successful and 8 of them attained maturity. In reverse direction out of 86 attempts, 22 had set fruits and only 7 of them attained maturity while the remaining fell down. Average number of seeds per berry was 17.50 in forward and 18.00 in reciprocal crosses. However, plant survival was $66.67 \%$ in 
both ways. Crosses between $S$. lucani $\times$ surattense var. white showed $7.89 \%$ and $6.94 \%$ fruit setting out of 76 and 72 attempts in forward and reciprocal direction, respectively. Out of 5 mature fruits of $S$. surattense var. white $\times$ lucani, two were seedless. The corssability index was 0.23 and 0.21 between $S$. surattense var. violet $\times$ lucani while 0.10 and 0.16 between $S$. surattense var. white $\times$ lucani in forward and reciprocal direction, respectively, suggested lower degree of crossability relationships.

\section{Meiosis in parents and hybrids}

Meiosis in parental lines showed 12 normal bivalents (Figs. 2-4), mostly ring shaped that disjuncted normally. The mean chiasma frequency were $22.83 \pm 0.83$ in S. lucani, $23.42 \pm$ 0.85 in $S$. surattense var. white and $23.52 \pm 0.38$ in $S$. surattense var. violet.

The interspecific hybrids showed irregular meiosis and chromosomal pairing at first metaphase was reduced (Table 2, Figs. 4-6). The earliest stages of meiosis were not discernible well as the chromosomes were badly entangled then. Some unpaired chromosomes could be made out at pachytene as less stained parts (Fig. 1). S. lucani $\times$ surattense var. violet meiocytes at diakinesis showed varying number of univalents ranging from zero to six

Table 1. Crossability relationships between $S$. surattense (var. violet and var. white) and $S$. lucani

\begin{tabular}{lcccc}
\hline \hline & $\begin{array}{c}\text { S. surattense } \\
\text { lucani } \\
\text { var. violet }\end{array}$ & $\begin{array}{c}\text { S. lucani } \\
\text { surattense } \\
\text { var. violet }\end{array}$ & $\begin{array}{c}\text { S. surattense } \\
\text { lucani } \\
\text { var. white }\end{array}$ & $\begin{array}{c}\text { S. lucanix } \\
\text { surattense } \\
\text { var. white }\end{array}$ \\
\hline Number of cross attempted & 102 & 86 & 72 & 76 \\
Number of successful cross & 28 & 22 & 26 & 20 \\
$\begin{array}{l}\text { Number of fruit attained } \\
\text { maturity }\end{array}$ & 8 & 7 & 5 & 6 \\
Number of seedless fruit & - & - & 2 & - \\
Per cent successful fruit & 7.84 & 8.13 & 6.94 & 7.98 \\
Average number of seeds/ & 17.50 & 18.00 & 18.00 & 14.50 \\
$\quad$ fruit & 16.00 & 5.35 & 10.00 & 7.40 \\
Per cent seed germination & 66.67 & 66.67 & 50.00 & 100.00 \\
Per cent survival & 0.23 & 0.21 & 0.10 & 0.16 \\
Crossability Index* & & & & \\
\hline
\end{tabular}

* After marks 1965.

per cell (average 2.18/PMC) and mean number of chiasmata per cell $16.71+1.52$, The average number of bivalents per PMC was 9.45; with most cells showing 3-5 rod and 5-7 ring shaped bivalents. A few PMCs showed 1-2 asymmetrical chain of tri- or hexavalents (Table 2, Figs. 6-8) and occasionally a Y-shaped trivalent and cross shaped quadrivalents (Fig. 6). Average chromosomal configurations in dividing cells of the reciprocal hybrid was 1.60 uni-, $10.13 \mathrm{bi}$-, and 0.38 chain-shaped trivalent with mean chiasma frequency per cell $17.13 \pm 2.37$, which was significantly lower than those of the parents $(\mathrm{P}<0.05)$.

Interspecific hybrid between $S$. lucani $\times$ surattense var. white showed 0-6 (Fig. 5) univalents, 7-10 bivalents, $0-2$ tri-, and $0-1$ tetravalent. The average configuration per PMC was 3.0 uni-, 9.71 bi-, 0.43 tri-, and 0.14 tetravalent with mean chiasma per PMC $16.57 \pm 2.38$ $(\mathrm{P}<0.05)$. In reciprocal hybrid meiocyte showed $0-4$ univalents $(1.60) .8-11$ bivalents $(10.60)$ and $0-2$ chain trivalent $(0.40)$ configuration with mean chiasma per cell $17.80 \pm 0.84$, which was significantly lower than those of the parents $(\mathrm{P}<0.05)$.

The interspecific $F_{1}$ hybrids indicated that both species retain homology to some extent due to occurrence of greater frequency of bivalents in PMCs and atleast seven ring bivalents have full homology to each other and remaining pairs of rod bivalents have partial homo- 


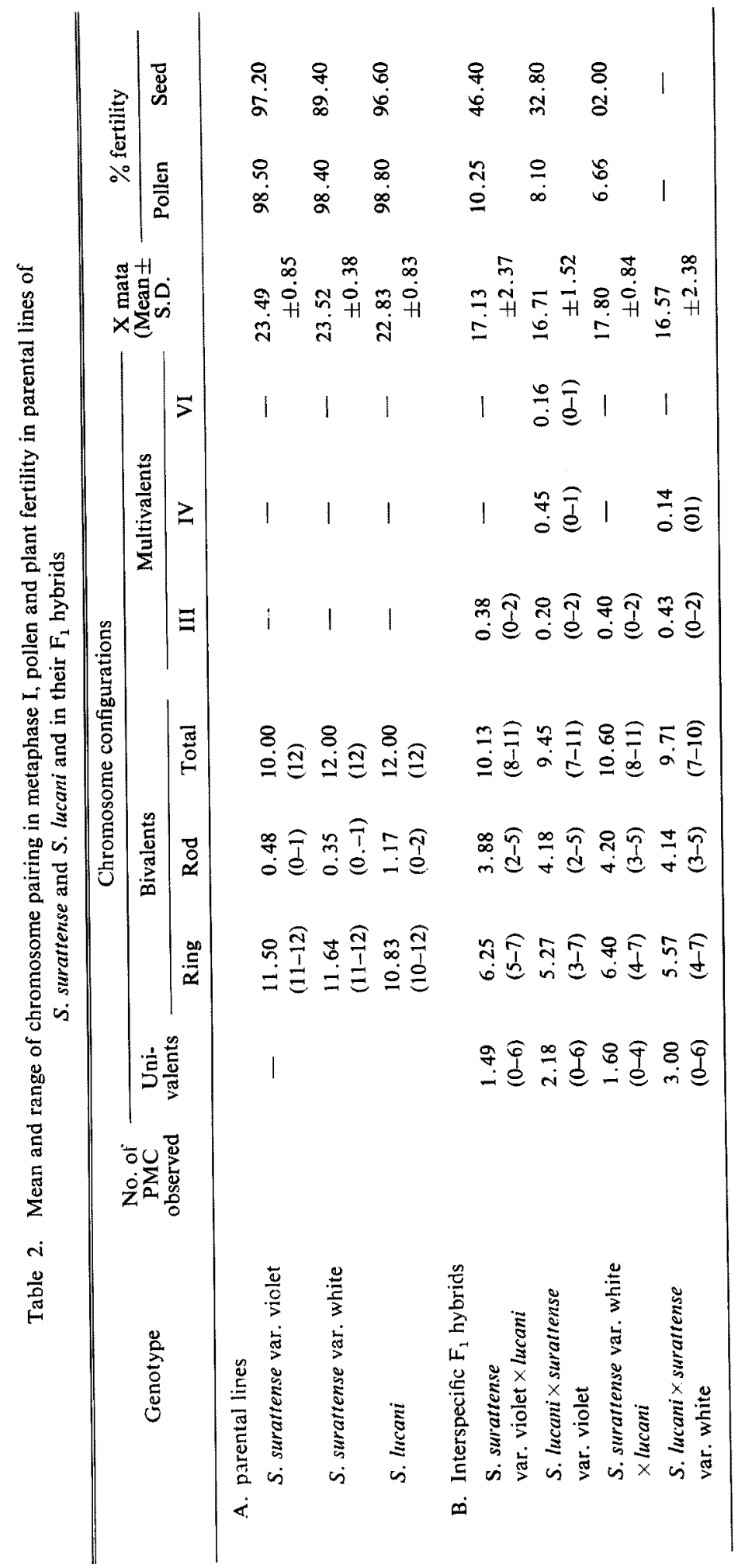



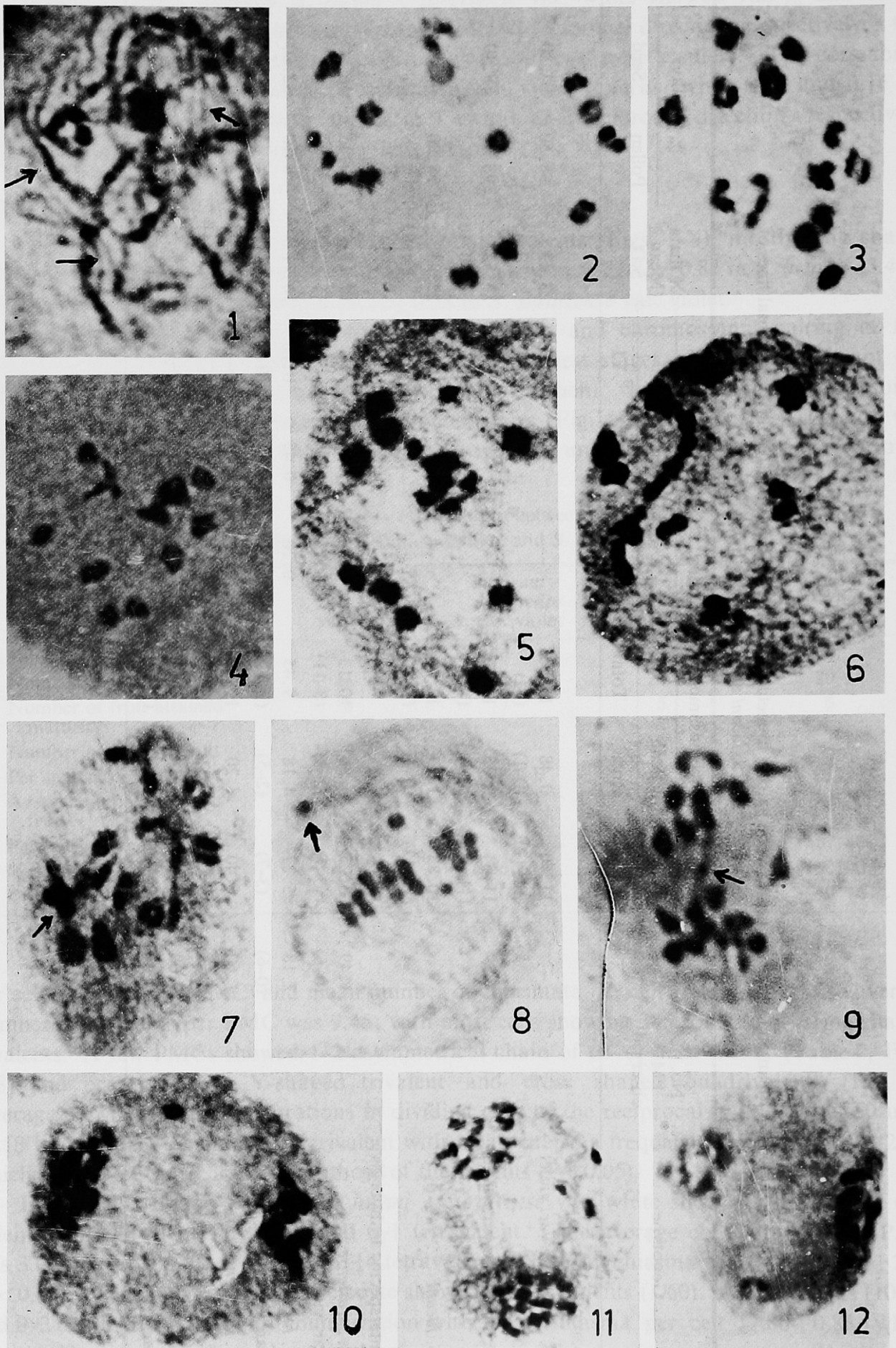

Figs. 1-12. Pollen mother cells of $S$. surattense var. violet, var. white, $S$. lucani and their $\mathrm{F}_{1}$ hybrids. All $\times 1600$ except $2-4 \times 2400$. 1, pachytene bivalents in $F_{1}$ hybrid $S$. lucani $\times$ surattense var. violet showing paired and unpaired chromsomes (Less staining region with arrow). 2, 3 and 4, diakinesis $S$. surattense var. violet, $S$. surattense var. white and $S$. lucani, respectively, showing normal 12 
logy. Significant reduction in chiasma frequency per cell and multivalent association in hybrids indicate that there are some degree of structural heterozygosity between pairing partners. Occurrence of chains of three of six chromosome in hybrid suggested heterozygosity for reciprocal translocation.

Later stages of hybrid meiocytes showed aberrant divisions. There were $7.97 \%$ unequal separation, single and double $(9.56 \%)$ bridges with $(3.19 \%)$ or without acentric fragments, 0-3 laggards $(14.74 \%)$ and $0-3$ eliminated chromosomes $(7.17 \%)$ in $S$. lucani $\times$ surattense var. violet and in reciprocal direction 7.46, 9.33, 2.61, 16.79 and $4.10 \%$ unequal separation, bridge, fragment, laggard and eliminated chromosomes, respectively, were seen.

$S$. lucani $\times$ surattense var. white showed $0-2$ single or double bridge with or without acentric fragment (Fig. 9), 0-3 laggards and 0-3 eliminated chromosomes (Figs. 10-11) in meiocytes and their percentage abnormalities are given in Table 3. The frequencies of these

Table 3. Percentage of chromosomal anomalies at anaphase $I$ in $F_{1}$ hybrid of S. surattense (var. violet and var. white) $\times$ lucani

\begin{tabular}{lccccccc}
\hline \multicolumn{1}{c}{ Genotype } & $\begin{array}{c}\text { No. of } \\
\text { PMCs } \\
\text { observed }\end{array}$ & $\begin{array}{c}\text { Normal } \\
\text { distri- } \\
\text { bution } \\
(\%)\end{array}$ & $\begin{array}{c}\text { Bridges } \\
(\%)\end{array}$ & $\begin{array}{c}\text { Fragment } \\
(\%)\end{array}$ & $\begin{array}{c}\text { Laggards } \\
(\%)\end{array}$ & $\begin{array}{c}\text { Eliminated } \\
\text { chromo- } \\
\text { somes } \\
(\%)\end{array}$ & $\begin{array}{c}\text { Unequal } \\
\text { distri- } \\
\text { bution } \\
(\%)\end{array}$ \\
\hline $\begin{array}{l}\text { S. surattense var. } \\
\text { violet } \times \text { lucani }\end{array}$ & 268 & 62.38 & 9.33 & 2.61 & 16.79 & 4.10 & 7.46 \\
$\begin{array}{l}\text { S. lucani } \times \text { surattense } \\
\text { var. violet }\end{array}$ & 251 & 60.56 & 956 & 3.19 & 14.74 & 7.17 & 7.97 \\
$\begin{array}{l}\text { S. surattense var. } \\
\text { white } \times \text { lucani }\end{array}$ & 236 & 57.63 & 10.59 & 2.97 & 18.22 & 5.51 & 8.05 \\
$\begin{array}{l}\text { S. lucani } \times \text { surattense } \\
\text { var. white }\end{array}$ & 249 & 52.21 & 9.24 & 2.41 & 19.67 & 9.24 & 9.64 \\
\hline
\end{tabular}

* Range.

reciprocal hybrids were $10.59,2.97,18.22$ and $5.51 \%$ bridges, fragment, laggard and eliminated chromosomes, respectively (Table 3 ).

These abnormalities, further, indicated genomic differences between $S$. lucani and both the varieties of $S$. surattense. Occurrence of chromatid bridge and acentric fragment proved heterozygosity for a paracentric inversion in the genomes. Acentric fragments were small with less frequency. So it can be assumed that the inversions are small and in subterminal in position.

These abnormalities of anaphase I also appeared in anaphase II (Table 4). However, a good percentage of PMCs of the hybrids showed normal telophase in forward and reciprocal direction. The presence of laggards or eliminated chromosomes disturbed the equational segregation of chromosomes resulting into imbalanced telophase nuclei. Eliminated chromosomes during MI and MII witnessed their unequal distribution and some chromosomes

bivalents. 5 , metaphase I, in $S$. surattense var. white $\times$ lucani showing 9 bivalents and 6 univalents. 6 , diakinesis in $S$. surattense var. violet $\times$ lucani showing 9 bivalents and chain of 6 chromosomes. 7 , diakinesis in $S$. lucani $\times$ surattense var. violet showing 7 bivalents, 2 trivalents (chain and $Y$-shaped) and 1 tetravalent (arrow). 8, metaphase I in $S$. lucani $\times$ surattense var. violet showing 9 bivalents, 1 trivalent and 3 univalents (in which one chromosome non oriented at equator, indicated by arrow). 9. anaphase $I$ in $S$. lucani $\times$ surattense var. white showing chromatid bridge with acentric fragment (arrow) and breakage of heteromorphic bivalent. 10-11, anaphase $I$ in $S$. lucani $\times$ surattense var. white showing eliminated chromosome(s). 12, formation of microunclei in $S$. lucani $\times$ surat tense var, violet at anaphase $\mathbf{I}$. 


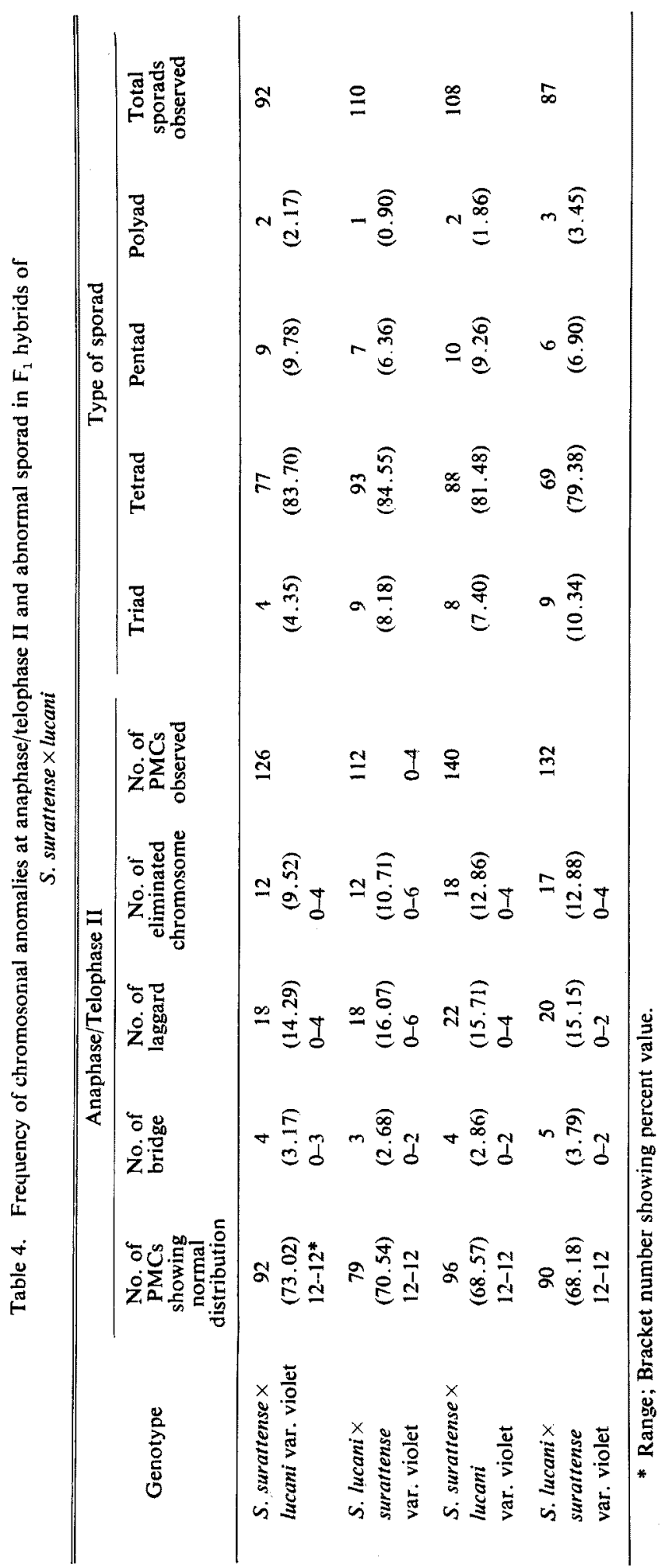


accumulated without order to form micronuclei (Table 4, Fig. 12).

\section{Pollen and plant fertility in parents and hybrids}

Parental lines were fully fertile. Interspecific hybrids showed poor pollen and plant fertility, e.g. in $S$. lucani $\times$ surattense var. violet pollen fertility in forward and reciprocal directions was $8.40 \%$ and $10.25 \%$, respectively, and in both ways such hybrids were partially fertile only. S. lucani $\times$ surattense var. white showed $6.58 \%$ fertile pollen in forward direction while the reverse hybrid was completely sterile.

\section{Discussion}

Data on crossability relationships have revealed low crossability index between $S$. lucani and surattense (both varieties) as very few seeds were produced by the hybrids between them even after a large number of cross pollinations. This incompatibility of genomes can be ascribed to the isolating mechanism, the wide seas and the spatial difference between India and Australia have aparted the populations since ages to lose homology to the extend now observable in the artificial hybrid. The capacity of hybridization between the two species is reduced because of self pollination. Stimulation of pollen germination after application of pollen germinating media on pistillate stimga indicates nutritional barrier for pollen germination. Likewise, production of parthenocarpic fruits in $S$. surattense var. white $\times$ lucani hybrid is due to stimulus of pollination alone as reported by Omidiji (1976) in African Solanum hybrids.

A convincing method for detecting cytogenetical and phylogenetic relationship between different taxa is study of pairing behaviour of chromosomes during meiosis of $F_{1}$ hybrids. This suggests the degree of chromosomal homology and structural differences between pairing partners. Chromosome pairing would induce chiasmatic chromosome associations also as chiasma investigated cytological phenomena in general. Reduction in chromosome pairing is influenced by chromosomal differences and the presence of pairing supression gene (Sears 1976).

Solanum hybrids have been characterized in showing less reduction in chromosome pairing and chiasma frequency, and yet, sterile (Marks 1965, Singh and Roy 1986). Recently few workers have reported structural hybridity in Solanum (Veerabhadra Rao and Rao 1977, Choudhuri 1981, Kirti and Rao 1981). In the present study $F_{1}$ of $S$. lucani $\times$ surattense var. violet and with var. white have shown irregular pairing that supported some degree of chromosomal differences between both the parents. Further, significant reduction in chiasma frequency corroborated the above contention that there is incomplete homozygosity between the genomes of $S$. lucani and $S$. surattense. Of the 10 bivalents that usually appeared in the hybrid 5-7 were of ring type indicating complete homology between 7 chromosomes of $S$. lucani and 7 chromosomes of $S$. surattense and incomplete homology between the pairing partners of the remaining rod shaped bivalents. Sometimes rod shaped bivalents showed outstretched chiasmata or could even appear as univalents due to perhaps early treminalization. The other three pairs of chromosomes indicated heterozygosity for reciprocal translocation. Asymmetrical chain of 3 or 6 chromosomes suggested unequal translocated segments. These chromosomes reduced chiasmata or could even show total failure of pairing. Special configurations such as $\mathrm{Y}$-shaped trivalents have suggested that for some interchanges there were interstitial break points. This type of higher chromosomal associations in Solanum hybrids were also reported by Kirti and Rao (1981) and Ramanna and Hermsen (1979). Moreover occurrence of chromatid bridge and acentric fragment of eliminated chromosomes at anaphase were the result of heterozygosity for a paracentric inversion. Lagging or unequal 
segregation of chromosomes produced defective pollen, which influenced pollen fertility of hybrids. This has given rise to a good number of abnormal sporads, besides the normal tetrads. The principal cause of hybrid sterility is meiosis followed by unequal segregation of chromosomes. Incomplete pairing, recombination of partially differentiated chromosomes, paracentric inversion etc. lead to the formation of chromosomally and genetically unbalanced gametes with many duplications and deficiencies.

Complete sterility in hybrid such as $S$. surattense var. white $\times$ lucani indicates that besides chromosomal differences this can be brought about by interaction between incompatible nuclear and cytoplasmic factors (Buck 1960, Omidiji 1974, Kirti and Rao 1983).

\section{Summary}

Interspecific hybrids between $S$. lucani and $S$. surattense (violet and white varieties both) were successful in forward and reciprocal directions. The crossability index between them was low, which suggests low degree of crossability relationships between hybridizing parents. Meiotic studies on parental genomes showed normal bivalents, most of which were ring shaped and chiasma frequency was high.

Interspecific hybrids showed abnormal synapsis and unpaired chromosomes/chromosome parts with less staining ability. Metaphase I was characterized by the appearance of univalents, chains of three or six chromosomes, $\mathrm{Y}$-shaped trivalent and rarely tetravalent association. Most PMCs contained 9 bivalents of which 5-7 were ring bivalents suggesting full homology between 7 chromosomes of $S$. surattense and 7 chromosomes of $S$. lucani, and the remaining 2 pairing partners exhibited partial homology by showing rod bivalents. Failure of synapsis in the rod bivalents could produce occasionally univalents only. Asymetrical chain made of three or six chromosomes indicated interchange of unequal segments due to heterozygosity for reciprocal translocation, in which 3 chromosomes from each parent were involved. Formation of $\mathrm{Y}$-shaped trivalents was due to joint of interstitial break points. Further, occurrence of chromatid bridge with or without acentric fragments, presence of univalents, lagging and eliminated chromosomes indicated heterozygosity between parental genomes which contributed to formation of sterile pollen. However, all hybrids showed partial fertility except $S$. lucani $\times$ surattense var. white which was completely sterile.

\section{Acknowledgement}

Financial support was provided by Council of Science and Technology, Govt. of Uttar Pradesh, India.

\section{References}

Brewbaker, J. L. and Kwack, B. H. 1963. The essential role of calcium ion in pollen germination and pollen tube growth. Amer. J. Bot, 50: 859-863.

Buck, R. W. 1960. Male sterility in interspecific hybrids of Solanum. J. Heredity 51 : $13-14$.

Choudhuri, H. C. 1981. Cytogenetical studies in a West African Solanum melongena L. hybrid ( $S$. melongena var. Giwa-2 $\times$ var. Giwa-1). Cytologia 46: 255-264.

Dhar, M. L., Dhawan, B. N., Prasad, C. R., Rastogi, R. P., Singh, K. K. and Tandon, J. S. $1974 . \quad$ Screening of Indian plants for biological activity part V. Indian J. Exp. Biol. 12: 512-523.

Heble, M. R. and Bhatt, B. 1976. Solasodine from curved spine mutants of Solanum khasianum Clarke. Indian J. Exp. Biol. 14 (4): 527-528.

Kirti, P. B. and Rao, B. G. S. 1981. Cytogenetic studies on the $F_{1}$ hybrid Solanum indicum $\times S$. torvum. Theor. Appl. Genet. 59: 303-306.

- and - 1982. Cytological studies on $F_{1}$ hybrids of Solanum integrifolium with S. melongena var. insanum. Genetica (Netherlands) 59: 127-131. 
- and - 1983. The cytogenetic basis of sterility in spinous Solanum hybrids. Caryologia 36 (2): 155-164.

Marks, G. E. 1965. Cytogenetic studies in tuberous Solanum species. III. Species relationships in some South and Central American species. New Phytologist 64: 293-306.

Omidiji, M. O. 1976. Crossability relationships between some species of Solanum, Lycopersicon and Capsicum cultivated in Nigeria. In: The Biology and Taxonomy of the Solanaceae. Acad. Press, London, pp. 599-604.

Omidiji, M. O. 1983. Cytomorphological studies of Solanum macrocarpon $F_{1}$ hybrid. Cytologia 48: 35-40.

Ramanna, M. S. and Hermsen, J. G. Th. 1979. Unique meiotic behaviour in $F_{1}$ plants from a cross between a non-tuberous and a tuberous Solanum species in section Petota. Euphytica 28: 9-15.

Rao, G. R. 1981. Results of interspecific cross pollination between Solanum melongena and Solanum incanum in eggplant breeding. Proc. Indian Nat. Acad. Sci. 47(6): 893-898.

Sears, E. R. 1976. Genetic control of chromosome pairing in wheat. Annu. Rev. Genet. 10: 31-51.

Singh, R. N. and Roy, S. K. 1986. Chromosome association and pollen fertility in Solanum melongena $\times S$. surattense hybrids. Cytologia 51: 85--93.

Veerabhadra Rao, S. and Rao, B. G. S. 1977. Screening of flowers in interspecific crosses of some spinous Solanum species. Curr. Sci. 46: 123-124.

Watt, J. M. and Breyer-Brandwijk, M. G. 1962. The medicinal and poisonous plants of Southern and Eastern Africa. 2nd ed. Edinburgh and London: Livingstone. 